\title{
Stent Retriever Thrombectomy in Patients Who Are Ineligible for Intravenous Thrombolysis: A Multicenter Retrospective Observational Study
}

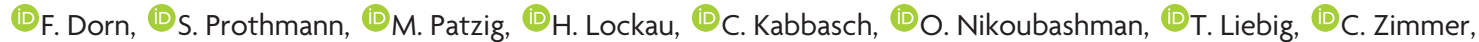

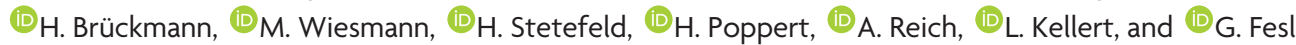

\begin{abstract}
BACKGROUND AND PURPOSE: Intravenous thrombolysis with rtPA is the standard of care for patients with acute ischemic stroke within 4.5 hours after symptom onset. However, a considerable number of patients are ineligible for IV thrombolysis due to various contraindications. Recent studies have proved the superiority of mechanical thrombectomy for patients with large-vessel occlusions in combination with IV rtPA compared with IV rtPA alone. We aimed to demonstrate the efficacy of mechanical thrombectomy for patients who are ineligible for IV rtPA.
\end{abstract}

MATERIALS AND METHODS: Patients from the stroke registries of 4 dedicated centers who were treated with mechanical thrombectomy from January 2010 to October 2014 were retrospectively evaluated. Inclusion criteria were the following: acute stroke due to proved large-artery occlusion, ineligibility for IV thrombolysis, and a timeframe of $\leq 4.5$ hours between stroke and the start of mechanical thrombectomy. Recanalization success, periprocedural complications, clinical outcome, and hemorrhages were evaluated.

RESULTS: One hundred thirty endovascular recanalization procedures were identified. The locations were the following: proximal ICA in 17 (13.1\%), terminus ICA in 25 (19.2\%), M1 segment in 77 (59.2\%), and M2 segment in 11 (8.5\%). $\mathrm{TICl} 2 \mathrm{~b} / 3$ results were achieved in 101 (77.7\%), and an $\mathrm{mRS}$ score of $0-2$ in 47 patients (37.9\%). There was a significant correlation between $\mathrm{TICl} 2 \mathrm{~b} / 3$ results and good clinical outcomes $(87.2 \%$ versus $6.8 \% ; P=.048)$. A good clinical result was most frequent when recanalization was achieved within 4.5 hours $(37 / 74=50 \%$ versus $10 / 50=20.0 \% ; P=.001)$. Symptomatic hemorrhage occurred in $13.1 \%$ of patients; mortality was $24.2 \%$. Periprocedural complications were recorded in 10 patients $(7.7 \%)$.

CONCLUSIONS: Mechanical thrombectomy can achieve good clinical outcomes in patients with acute large-artery occlusion ineligible for IV thrombolysis, in particular when recanalization is reached early.

ABBREVIATIONS: ESCAPE = Endovascular Treatment for Small Core and Anterior Circulation Proximal Occlusion With Emphasis on Minimizing CT to Recanalization Times; EXTEND IA = Extending the Time for Thrombolysis in Emergency Neurologic Deficits-IntraArterial; MR CLEAN = Multicenter Randomized Clinical Trial of Endovascular Treatment for Acute Ischemic Stroke in the Netherlands; SWIFT PRIME = Solitaire With the Intention for Thrombectomy as Primary Endovascular Treatment Trial; REVASCAT = Randomized Trial of Revascularization with the Solitaire FR Device Versus Best Medical Therapy in the Treatment of Acute Stroke Due to Anterior Circulation Large Vessel Occlusion Presenting within Eight Hours of Symptom Onset

ntravenous treatment with recombinant tissue-plasminogen activator has been proved effective and has been the standard therapy for patients with acute ischemic stroke within 4.5

Received April 26, 2015; accepted after revision June 27.

From the Departments of Neuroradiology and Radiology (F.D., H.L., C.K., T.L.) and Neurology (H.S.), University Hospital of Cologne, Cologne, Germany; Departments of Neuroradiology (S.P., C.Z.) and Neurology (H.P.), Klinikum Rechts der Isar, Technical University, Munich, Germany; Departments of Neuroradiology (F.D., M.P., H.B., G.F.) and Neurology (L.K.), University Hospital of Munich, Munich, Germany; and Departments of Neuroradiology (O.N., M.W.) and Neurology (A.R.), University Hospital of Aachen, Aachen, Germany.

F. Dorn and S. Prothmann contributed equally to this work.

Please address correspondence to Franziska Dorn, MD, University Hospital of Munich, Department of Neuroradiology, Marchioninistr 15, 81377 Munich, Germany; e-mail: franziska.dorn@med.uni-muenchen.de

http://dx.doi.org/10.3174/ajnr.A4520 hours after symptom onset for many years. ${ }^{1}$ However, the percentage of patients eligible for treatment with IV thrombolysis is limited, not only because of the restricted time window ${ }^{2}$ but also due to various medical conditions such as recent surgery, anticoagulation, coagulation abnormalities, and history of intracranial hemorrhage. ${ }^{3}$

Patients with acute stroke symptoms secondary to a large-artery occlusion are at high risk of poor clinical outcome. Furthermore, they are known to respond poorly to IV rtPA alone. ${ }^{4-8}$

During the past decade, several endovascular techniques have been established to improve the success of recanalization and thus the clinical outcomes of these patients, including intra-arterial thrombolysis, mechanical thrombectomy, and permanent stent angioplasty. ${ }^{9-12}$ Fully retrievable stent-based thrombectomy devices (stent retrievers) were introduced in $2008^{13}$ and today are 
the technical standard of care for endovascular recanalization treatment in most stroke centers. While several studies and case series have shown high recanalization success of $>80 \%-90 \%,{ }^{14-19}$ the first randomized trials proving a clear clinical benefit compared with sole IV therapy were published only recently. ${ }^{20-24}$

The aim of this study was to complement the existing data by proving the efficacy of endovascular treatment for the subgroup of patients with large-artery occlusions located in the anterior circulation who are ineligible for primary IV thrombolysis within a time window of 4.5 hours.

\section{MATERIALS AND METHODS \\ Patient Selection}

From the stroke registries of 4 stroke centers, we retrospectively evaluated all patients who underwent endovascular therapy between January 2010 and October 2014 and met the following criteria: acute stroke symptoms secondary to large-artery occlusion and contraindications for IV thrombolysis despite a time from symptom onset to the start of endovascular therapy of $\leq 4.5$ hours. One-hundred eight patients $(83.1 \%)$ underwent the CT stroke protocol, and 22 patients (16.9\%), MR imaging.

The decision for treatment for all patients was based on the clinical presentation and the imaging findings. A team of stroke neurologists examined all patients on admission, and the National Institutes of Health Stroke Scale scores were recorded. The patients included in this series had an NIHSS score of at least 10 or fluctuating symptoms. All patients underwent CT or MR imaging before treatment. If possible, multiparametric imaging was performed by using CT/CT angiography and CT perfusion imaging or MR imaging/MR angiography, including the acquisition of FLAIR images, diffusion-weighted images, and a gradient-echo $\mathrm{T} 2{ }^{*}$ sequence. Imaging criteria for exclusion from endovascular therapy were visible infarction of more than one-third of the vessel territory, no relevant mismatch on CT perfusion imaging, and evidence of hemorrhage. There was no limit to the patient age.

\section{Procedural Data}

Final reperfusion success was rated on the basis of the Thrombolysis In Cerebral Infarction scale. Successful reperfusion was defined as TICI scores $2 \mathrm{~b}$ and $3 .^{25}$ The start of angiography was defined as the time of the femoral artery puncture, and the first persistent reperfusion result was used for time-to-reperfusion measures.

\section{Endovascular Procedure}

All except 8 procedures were performed with the patient under general anesthesia. Endovascular treatment consisted of arterial catheterization of the occluded vessel with a microcatheter and delivery of a stent retriever by withdrawal of the microcatheter. This was followed by a maneuver to withdraw the stent retriever under either continuous aspiration by using a distal access catheter or proximal balloon occlusion. The procedure was repeated until the best possible recanalization result was achieved. Procedures involved the following stent retrievers: Solitaire FR (Covidien, Irvine, California) in 88 (67.7\%), Trevo/Trevo ProVue (Stryker, Kalamazoo, Michigan) in 32 (24.6\%), pREset thrombus retriever (Phenox, Bochum, Germany) in 7 (5.4\%), and a combination of Solitaire and Trevo in 3 procedures $(2.3 \%)$.

\section{Follow-Up Imaging and Clinical Outcome}

All patients underwent CT and/or MR imaging at $18 \pm 6$ hours after the intervention. The images were rated for hemorrhagic transformation or cerebral hemorrhage. According to the criteria of the European Cooperative Acute Stroke Study III, symptomatic hemorrhage was defined as any intracranial hemorrhage with clinical deterioration, as indicated by an NIHSS score that was $>4$ points or more than the value at baseline. ${ }^{1}$

Good clinical outcome after 3 months was defined as an mRS of $0-2$.

\section{Statistical Analysis}

Statistical analysis was performed by using SPSS 22.0.0.0 (IBM, Armonk, New York). To test categoric variables for differences, the $\chi^{2}$ test was performed. Mann-Whitney $U$ tests and Student $t$ tests were used for comparison of continuous variables. A $P$ value of $<.05$ was statistically significant.

\section{RESULTS}

We identified 130 patients with large-vessel occlusion in the anterior circulation who underwent endovascular recanalization procedures within 4.5 hours after symptom onset and were ineligible for IV thrombolysis. Table 1 gives an overview of the relevant patient data. The mean age was 68.8 years (range, 18-90 years), 64 patients were women (49.2\%), and 66 patients $(50.8 \%)$ were men. The occlusions were located as follows: the proximal ICA in $17(13.1 \%)$, ICA terminus in 25 (19.2\%), proximal M1 segment in $71(54.6 \%)$, postbifurcal M1 segment in $6(4.6 \%)$, and M2 segment in 11 (8.5\%). A TICI $2 b$ or 3 recanalization result was achieved in 101/130 patients (77.7\%). Anticoagulation with phenprocoumon was the most common contraindication for IV thrombolysis (44 patients, $33.8 \%)$. Twenty-one patients $(16.2 \%)$ had a recent history of stroke with corresponding lesions on MR imaging, and 23 patients $(17.7 \%)$ had a history of recent surgery. Ten patients (7.7\%) with evidence for an extracranial occlusion of the ICA were not treated with IV thrombolysis but with antiplatelet medication in preparation for stent placement to reduce the risk of hemorrhage, and 6 patients $(4.6 \%)$ were under full-dose heparin for numerous disorders. Two patients (1.5\%) had not received IV rtPA due to epileptic onset of stroke symptoms; 5 (3.8\%), because of known metastasizing cancer; 2 (1.5\%), because of gastrointestinal bleeding; $2(1.5 \%)$, because of previous trauma; 3 (2.3\%), because of a history of intracranial hemorrhage; $1(0.8 \%)$, because of diagnosed coagulative disorder; and $1(0.8)$, because of an intracranial aneurysm detected by CT angiography. In 10 patients $(7.7 \%)$, contraindication could not be evaluated. Table 2 gives a detailed overview of the contraindications.

The NIHSS score at admission was available in 120/130 patients $(92.3 \%)$. The mean NIHSS score was $16.32 \pm 6.40$ (minimum, 2 with fluctuating symptoms; maximum, 34). Modified Rankin Scale scores after 3 months were available in 124/130 patients (95.4\%). A good clinical outcome (mRS 0-2) was achieved 
Table 1: Relevant patient data listed for all patients ${ }^{a}$

\begin{tabular}{|c|c|}
\hline Patient Data & \\
\hline No. of patients & 130 \\
\hline Mean age (yr) & $68.8(\min .18, \max .90)$ \\
\hline \multicolumn{2}{|l|}{ Sex } \\
\hline Female & $64(49.2 \%)$ \\
\hline Male & $66(50.8 \%)$ \\
\hline $\begin{array}{l}\text { Median NIHSS score on admission } \\
\text { (range) }\end{array}$ & $16.32 \pm 6.4(\min .2, \max .34)$ \\
\hline \multicolumn{2}{|l|}{ Intracranial occlusion site } \\
\hline Proximal ICA + distal ICA/MCA & $17(13.1 \%)$ \\
\hline Terminus ICA & 25 (19.2\%) \\
\hline M1 & $77(59.2 \%)$ \\
\hline Main branch & $71(54.6 \%)$ \\
\hline Postbifurcal segment & $6(4.6 \%)$ \\
\hline $\mathrm{M} 2$ & $11(8.5 \%)$ \\
\hline \multicolumn{2}{|l|}{ Reperfusion results } \\
\hline $\mathrm{TICl} O$ & $5(3.6 \%)$ \\
\hline $\mathrm{TICl} 1$ & $4(3.1 \%)$ \\
\hline $\mathrm{TICl} 2 \mathrm{a}$ & $22(15.4 \%)$ \\
\hline $\mathrm{TICl} 2 \mathrm{~b}$ & $46(35.4 \%)$ \\
\hline $\mathrm{TICl} 3$ & $55(42.3 \%)$ \\
\hline $\begin{array}{l}\text { Time from stroke onset to groin } \\
\text { puncture (minutes) (mean) }\end{array}$ & $175.7 \pm 45.4(\min .65, \max .270)$ \\
\hline $\begin{array}{l}\text { Time from stroke onset to final } \\
\text { recanalization (minutes) (mean) }\end{array}$ & $246.0 \pm 71.7(\min .94, \max .432)$ \\
\hline \multicolumn{2}{|l|}{ mRS after 3 months $(n=124)$} \\
\hline 0 & $17(13.1 \%)$ \\
\hline 1 & $12(9.2 \%)$ \\
\hline 2 & $18(13.8 \%)$ \\
\hline 3 & $17(13.1 \%)$ \\
\hline 4 & $16(12.3 \%)$ \\
\hline 5 & 14 (10.8\%) \\
\hline 6 & $30(23.1 \%)$ \\
\hline Symptomatic hemorrhage & 17 Patients (13.1\%) \\
\hline Periprocedural complications & $10(7.7 \%)$ \\
\hline SAH & $6(4.6 \%)$ \\
\hline Thrombus lost & $1(0.8 \%)$ \\
\hline Dissection & $2(1.6 \%)$ \\
\hline Loss of device & $2(1.6 \%)$ \\
\hline
\end{tabular}

Note:-Max. indicates maximum; min, minimum.

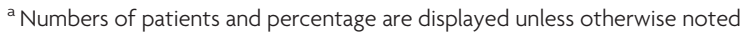

Table 2: Summary of contraindications against IV thrombolysis

\begin{tabular}{lc}
\hline \multicolumn{1}{c}{ Contraindication } & No. of Patients $(\boldsymbol{n}=130)$ \\
\hline Phenprocoumon (INR $>1.7)$ & $44(33.8 \%)$ \\
Recent surgery & $23(17.7 \%)$ \\
Recent stroke & $21(16.2 \%)$ \\
Emergency stentangioplasty & $10(7.7 \%)$ \\
IV heparin & $6(4.6 \%)$ \\
Metastasizing cancer & $5(3.8 \%)$ \\
History of ICH & $3(2.3 \%)$ \\
Previous trauma & $2(1.5 \%)$ \\
Epileptic onset & $2(1.5 \%)$ \\
Gastrointestinal bleeding & $2(1.5 \%)$ \\
Coagulative disorder & $1(0.8 \%)$ \\
Intracranial aneurysm & $1(0.8 \%)$ \\
Not evaluable & $10(7.7 \%)$ \\
\hline
\end{tabular}

Note:-INR indicates international normalized ratio; ICH, intracerebral hemorrhage.

in $47 / 124$ patients $(37.9 \%)$. The recanalization was successful (TICI $2 \mathrm{~b} / 3$ ) in $101 / 130$ patients $(77.7 \%)$. Forty-one $(87.2 \%)$ of the 47 patients with a good clinical outcome after 3 months had TICI $2 \mathrm{~b} / 3$ recanalization, whereas only 6 had a TICI $0-2 \mathrm{a}$ result $(6.8 \% ; P=.048)$. The mean time from stroke onset to groin puncture was $175.7 \pm 45.4$ minutes (minimum, 65 minutes; maximum, 270 minutes), and the mean time from stroke onset to final recanalization was $246.0 \pm 71.7$ minutes (minimum, 94; maximum, 432 minutes). A favorable clinical outcome was more frequent in patients with an occlusion of the M2 (5/11 patients,
45.5\%) and M1 segments (30/76 patients, 40.5\%) and was least frequent in patients with an occlusion of the terminus ICA (6/24, $25.0 \%$ ). A good clinical result was more frequent when recanalization was achieved within 4.5 hours compared with patients with longer recanalization times $(37 / 74=50 \%$ versus $10 / 50=20.0 \%$; $P=.001)$. If recanalization was achieved within 6 hours from onset $(n=107), 43$ patients $(40.2 \%)$ had a good outcome, whereas in only 4 of 17 patients $(23.5 \%)$ exceeding the time window of 6 hours was a good outcome noted $(P=.085)$.

The mean number of passages was 3.3. ${ }^{1-15}$ A good recanalization result (TICI $2 \mathrm{~b}$ or 3 ) was most likely in procedures with only 1 stent retriever passage compared with procedures with $\geq 2$ stent retriever passages $(25 / 27=92.6 \%$ versus $76 / 103=73.8 \%$; $P=$ .039). Furthermore, the chance for a good clinical outcome was significantly higher after a recanalization that required only 1 passage $(16 / 26=61.5 \%$ versus $31 / 98=31.6 \% ; P=.007)$.

Altogether, intracranial hemorrhage was detected in 37 patients $(28.5 \%)$, of whom 17 had symptomatic hemorrhages $(13.1 \%)$. Intracranial hemorrhage occurred in $4 / 44$ patients $(9.1 \%)$ who were under sufficient anticoagulation with phenprocoumon at the time of stroke (international normalized ratio $>1.7)$ and in $3 / 6$ patients who were under effective IV heparin at the time of stroke $(50.0 \%)$. The incidence of hemorrhage was $66.7 \%(2 / 3)$ in patients with a history of intracerebral hemorrhage, $13.0 \%$ in patients with history of recent surgery $(3 / 23)$, $14.3 \%(3 / 21)$ in patients with recent ischemic stroke, and 20.0\% $(1 / 5)$ in patients who were not eligible for IV thrombolysis because of metastasizing cancer. The 1 patient with a previously diagnosed coagulative disorder did not develop hemorrhage. None of the patients who received antiplatelet medication for subsequent extra- or intracranial stent placement experienced hemorrhage. The mortality rate after 3 months was $24.2 \%$ (30/124 patients). Periprocedural complications occurred in 10 patients (7.7\%): subarachnoid hemorrhage in $6(4.6 \%)$, thrombus lost with occlusion of a previously nonaffected territory (A2 segment in 1 patient [0.8\%], dissection in 1 [0.8\%], and loss of the device in $2[1.6 \%])$.

\section{DISCUSSION}

To the best of our knowledge, we present the largest series of patients with acute occlusions of anterior large intracranial arteries who were ineligible for IV treatment and were primarily referred to sole endovascular therapy by using stent retrievers. So far, retrospective studies and prospective trials providing evidence for the benefit of endovascular treatment in this specific patient group are nonexistent. The Thrombectomy in Patients Ineligible for IV tPA trial (THRILL) was planned with the intention of showing a benefit of stent retriever based thrombectomy in patients who were ineligible for IV fibrinolysis, but enrollment was stopped and the results of this multicentric German/Austrian study are not available. ${ }^{26}$

Since the introduction of stent retrieval in $2008,{ }^{13}$ several case series have proved the technical effectiveness of the method, with potentially high rates of successful recanalization in patients with acute stroke symptoms secondary to largevessel occlusion. Furthermore, the superiority of stent retrievers in terms of revascularization abilities and clinical success in 
comparison with the first-generation Merci clot retriever devices (Concentric Medical, Mountain View, California) has been verified in 2 randomized studies. ${ }^{27,28}$ However, before December 2014, the only proved effective treatment for acute ischemic stroke was IV thrombolysis. This has now changed with the publication of 4 randomized studies: Multicenter Randomized Clinical Trial of Endovascular Treatment for Acute Ischemic Stroke in the Netherlands (MR CLEAN), ${ }^{20}$ Endovascular Treatment for Small Core and Anterior Circulation Proximal Occlusion With Emphasis on Minimizing CT to Recanalization Times (ESCAPE), ${ }^{21}$ Extending the Time for Thrombolysis in Emergency Neurologic Deficits-Intra-Arterial (EXTEND IA), ${ }^{22}$ Solitaire With the Intention for Thrombectomy as Primary Endovascular Treatment Trial (SWIFT PRIME), ${ }^{23}$ and the Randomized Trial of Revascularization with the Solitaire FR Device Versus Best Medical Therapy in the Treatment of Acute Stroke Due to Anterior Circulation Large Vessel Occlusion Presenting within Eight Hours of Symptom Onset (REVASCAT) ${ }^{24}$ All of these studies compared endovascular treatment with IV thrombolysis alone, and all confirmed a benefit of the endovascular approach for certain patients.

Stent retriever devices were used in $82 \%$ and $86 \%$ of the interventional arms of MR CLEAN and ESCAPE, respectively, and in $100 \%$ of the interventional arms of EXTEND-IA, SWIFT PRIME, and REVASCAT. We used stent retrievers in all cases, resulting in a recanalization success of $77.7 \%$ (TICI $2 \mathrm{~b} / 3$ ). This rate is within the range of ESCAPE (72.4\%), EXTEND-IA (86.2\%), and SWIFT PRIME $(88.0 \%)$ and higher compared with the rather modest successful recanalization rate of MR CLEAN (58.7\%).

The rate of good clinical outcomes varied widely in the recently published randomized trials, from $32.6 \%$ in MR CLEAN to $71.4 \%$ in EXTEND-IA. In our series, the clinical result after 3 months was available in a considerably high number of patients (95.4\%), and an mRS of $0-2$ was reached by $37.9 \%$ of them. Compared with the results of MR CLEAN, the higher percentage of successful recanalization certainly contributes to the better clinical outcome in our series; furthermore, the median time from stroke onset to groin puncture was shorter in our series (176 minutes) compared with MR CLEAN (260 minutes). However, the recanalization times were also shorter compared with ESCAPE (241 minutes) and EXTEND-IA, and both studies resulted in a higher percentage of patients with a favorable clinical outcome. We reason that comorbidities in our patient cohort ineligible for IV therapy contributed to the lower rate of good clinical outcomes compared with these studies.

Another parameter that should be discussed in this context is the lack of IV thrombolysis in our patient group. Intravenous thrombolytic treatment is frequently performed in patients with larger-artery occlusions before endovascular treatment by a "bridging" concept. However, the additional benefit from this regimen is unclear. Whereas the stent retriever series of Dávalos et $\mathrm{al}^{15}$ showed that patients had significantly better outcomes after IV thrombolysis and stent retriever thrombectomy compared with patients who were treated with stent retriever thrombectomy alone, this result could not be verified in the following Solitaire FR Thrombectomy for Acute Revascularisation trial (STAR) ${ }^{17}$ or other studies. Most patients in the interventional arm of MR CLEAN (87.1\%), ESCAPE (72.7\%), and REVASCAT (68.0\%) and all of the patients in the interventional arm of EXTEND-IA and SWIFT PRIME received IV thrombolysis before endovascular treatment, whereas due to various contraindicating conditions, none of the patients in our study received IV bridging therapy. We cannot know whether additional IV thrombolysis would have changed the number of patients with a favorable clinical outcome in our series significantly, and we cannot exclude this factor contributing to the comparably low number of patients with good clinical results despite successful recanalization in our series (at least when compared with ESCAPE, EXTEND-IA and SWIFT PRIME). Certainly, further evaluation and discussion of this matter will be necessary.

The exciting results of MR CLEAN, ESCAPE, EXTEND-IA, SWIFT PRIME, and REVASCAT will potentially change the guidelines for acute stroke management regimens in the near future. Until then endovascular recanalization is limited to decisions on a case-by-case basis, and IV thrombolysis remains the recommended standard of care for all patients with ischemic stroke within a time window of 4.5 hours. Henceforth, careful selection of patients and an evidence-based definition of subgroups that most likely benefit from endovascular therapy will be necessary to allow the development of responsible decision algorithms.

Contraindications for IV thrombolysis are frequent and most commonly include anticoagulative abnormalities and a history of recent surgery. Furthermore, IV thrombolysis is avoided in patients with conceivable indications for acute stent placement (eg, due to a dissection or stenosis) to avoid bleeding complications. According to most institutional guidelines, therapy for patients with contraindications for IV thrombolysis is limited to (noncausal) medical care, including the control of blood pressure and laboratory and vital parameters in a dedicated stroke care unit. Particularly for these patients, the chance of a (causal) endovascular treatment approach addressing the underlying pathology in the acute stroke phase may be of great benefit.

Certainly, the potential benefit of any medical therapy has to be balanced against a potential risk for adverse events. We found a periprocedural complication rate of $7.7 \%$ in our series, which is comparable with the results of the MR CLEAN and other trials and consisted of SAH, thrombus loss with subsequent infarction in previously not affected vessel territories, hemodynamically relevant dissections of extracranial arteries, and loss of devices.

Symptomatic intracranial hemorrhage after mechanical thrombectomy occurs in $4 \%-12 \%$ in larger case series and trials. ${ }^{14-19}$ Symptomatic hemorrhage was not increased in the interventional arm compared with the control group in MR CLEAN (7.7\% versus $6.4 . \%)$, ESCAPE (3.6\% versus $2.7 \%$ ), EXTEND-IA ( $0 \%$ for Solitaire, $6 \%$ for controls), SWIFT PRIME (0\% versus $3.1 \%$ ), and REVASCAT (1.9\% in both groups). In our series, symptomatic hemorrhage occurred in $13.1 \%$ of patients; it occurred in a high percentage of patients who developed stroke under IV heparin $(50 \%)$ but in $<10 \%$ of patients who were under phenprocomoun at the time of stroke. However, due to the small 
number of patients with IV heparin in our series, these results have to be interpreted carefully.

The present study has several limitations, and the results have to be interpreted with care. Due to its retrospective design, this multicenter study is prone to selection bias. There is no control group and no randomized patient selection. In addition, the patient cohort is not homogeneous for various reasons (eg, the included patients had acute strokes of different etiologies and with different vessel-occlusion patterns).

\section{CONCLUSIONS}

Our series indicates a potential benefit of stent retriever-based thrombectomy in patients with large-artery occlusions of the anterior circulation who are ineligible for IV thrombolysis. Successful and early recanalization was the most important factor for a good clinical outcome. Further prospective, controlled randomized studies will be necessary to prove the effectiveness of endovascular therapy for this specific patient group.

Disclosures: Sascha Prothmann-UNRELATED: Consultancy: phenox (proctor); Grants/Grants Pending: DFG grant, Flowmodel Aneurysm (grant pending); Payment for Lectures (including service on Speakers Bureaus): Boston Scientific, Covidien, Travel/Accommodations/Meeting Expenses Unrelated to Activities Listed: Acandis, AB Medica, phenox, Sequent Medical, MicroVention, Covidien. Thomas LiebigUNRELATED: Consultancy: Sequent Medical, Stryker, Acandis, Comments: consultant and proctor. Martin Wiesmann—UNRELATED: consultancy: Stryker Neurovascular, Philips; Grants/Grants Pending: Covidien, ${ }^{\star}$ MicroVention*; Payment for Lectures (including service on Speakers Bureaus): Bracco, Siemens; Royalties: Springer; Payment for Development of Educational Presentations: Abbott, ${ }^{*}$ AB Medica, ${ }^{*}$ Acandis, * Bayer, , Bracco, ${ }^{\star}$ B. Braun Medical, ${ }^{*}$ Codman Neurovascular, ${ }^{*}$ Covidien, ${ }^{*}$ Dahlhausen, ${ }^{\star}$ MicroVention, ${ }^{*}$ Penumbra, ${ }^{*}$ phenox, ${ }^{*}$ Philips Healthcare, ${ }^{*}$ Siemens, ${ }^{*}$ St. Jude, ${ }^{*}$ Stryker Neurovascular. ${ }^{*}$ Henning Stetefeld_UNRELATED: Travel/Accommodations/Meeting Expenses Unrelated to Activities Listed: Pfizer, Boehringer Ingelheim, Bayer, Comments: subsidized travel, accommodations, and meeting expenses. Holger Poppert-UNRELATED: board membership: Deutsche Stiftung Neurologie*; Consultancy: Bayer Healthcare, Boehringer Ingelheim, Daiichi Sankyo; Payment for Lectures (including service on Speakers Bureaus): Bayer Healthcare, Boehringer Ingelheim, Bristol-Myers Squibb, Roche; Travel/Accommodations/Meeting Expenses Unrelated to Activities Listed: Boehringer Ingelheim.* *Money paid to the institution.

\section{REFERENCES}

1. Hacke W, Kaste M, Bluhmki E, et al; ECASS Investigators. Thrombolysis with alteplase 3 to $\mathbf{4} .5$ hours after acute ischemic stroke. N Engl J Med 2008;359:1317-29 CrossRef Medline

2. Lees KR, Bluhmki E, von Kummer R, et al; ECASS, ATLANTIS, NINDS and EPITHET rt-PA Study Group. Time to treatment with intravenous alteplase and outcome in stroke: an updated pooled analysis of ECASS, ATLANTIS, NINDS, and EPITHET trials. Lancet 2010;375:1695-703 CrossRef Medline

3. Jauch EC, Saver JL, Adams HP Jr, et al; American Heart Association Stroke Council; Council on Cardiovascular Nursing; Council on Peripheral Vascular Disease; Council on Clinical Cardiology. Guidelines for the early management of patients with acute ischemic stroke: a guideline for healthcare professionals from the American Heart Association/American Stroke Association. Stroke 2013;44: 870-947 CrossRef Medline

4. Alexandrov AV. Ultrasound enhanced thrombolysis for stroke. Int J Stroke 2006;1:26-29 CrossRef Medline

5. Bhatia $\mathrm{R}$, Hill MD, Shobha $\mathrm{N}$, et al. Low rates of acute recanalization with intravenous recombinant tissue plasminogen activator in ischemic stroke: real-world experience and a call for action. Stroke 2010;41:2254-58 CrossRef Medline

6. Riedel CH, Zimmermann P, Jensen-Kondering U, et al. The importance of size: successful recanalization by intravenous thromboly- sis in acute anterior stroke depends on thrombus length. Stroke 2011; 42:1775-77 CrossRef Medline

7. Lindsberg PJ, Mattle HP. Therapy of basilar artery occlusion: a systematic analysis comparing intra-arterial and intravenous thrombolysis. Stroke 2006;37:922-28 CrossRef Medline

8. von Kummer R, Hacke W. Safety and efficacy of intravenous tissue plasminogen activator and heparin in acute middle cerebral artery stroke. Stroke 1992;23:646-52 CrossRef Medline

9. Furlan A. Intra-arterial prourokinase for acute ischemic stroke: the PROACT II Study — a randomized controlled trial. JAMA 1999;282: 2003-11 CrossRef Medline

10. Smith WS, Sung G, Saver J, et al. Mechanical thrombectomy for acute ischemic stroke: final results of the Multi MERCI trial. Stroke 2008;39:1205-12 CrossRef Medline

11. Smith WS, Sung G, Starkman S, et al; MERCI Trial Investigators. Safety and efficacy of mechanical embolectomy in acute ischemic stroke: results of the MERCI trial. Stroke 2005;36:1432-8 CrossRef Medline

12. Penumbra Pivotal Stroke Trial Investigators. The Penumbra Pivotal Stroke trial: safety and effectiveness of a new generation of mechanical devices for clot removal in intracranial large vessel occlusive disease. Stroke 2009;40:2761-68 CrossRef Medline

13. Pérez MA, Miloslavski E, Fischer S, et al. Intracranial thrombectomy using the Solitaire stent: a historical vignette. J Neurointerv Surg 2012;4:e32 CrossRef Medline

14. Castaño C, Dorado L, Guerrero C, et al. Mechanical thrombectomy with the Solitaire $\mathrm{AB}$ device in large artery occlusions of the anterior circulation: a pilot study. Stroke 2010;41:1836-40 CrossRef Medline

15. Dávalos A, Pereira VM, Chapot R, et al. Retrospective multicenter study of Solitaire FR for revascularization in the treatment of acute ischemic stroke. Stroke 2012;43:2699-705 CrossRef Medline

16. Dorn F, Stehle S, Lockau H, et al. Endovascular treatment of acute intracerebral artery occlusions with the Solitaire stent: single-centre experience with 108 recanalization procedures. Cerebrovasc Dis 2012;34:70-77 CrossRef Medline

17. Pereira VM, Gralla J, Davalos A, et al. Prospective, multicenter, single-arm study of mechanical thrombectomy using Solitaire Flow Restoration in acute ischemic stroke. Stroke 2013;44:2802-07 CrossRef Medline

18. Roth C, Papanagiotou P, Behnke S, et al. Stent-assisted mechanical recanalization for treatment of acute intracerebral artery occlusions. Stroke 2010;41:2559-67 CrossRef Medline

19. San Román L, Obach V, Blasco J, et al. Single-center experience of cerebral artery thrombectomy using the TREVO device in 60 patients with acute ischemic stroke. Stroke 2012;43:1657-59 CrossRef Medline

20. Berkhemer OA, Fransen PS, Beumer D, et al. A randomized trial of intraarterial treatment for acute ischemic stroke. N Engl J Med 2015; 372:11-20 CrossRef Medline

21. Goyal M, Demchuk AM, Menon BK, et al; ESCAPE Trial Investigators. Randomized assessment of rapid endovascular treatment of ischemic stroke. N Engl J Med 2015;372:1019-30 CrossRef Medline

22. Campbell BC, Mitchell PJ, Kleinig TJ, et al; the EXTEND-IA Investigators. Endovascular therapy for ischemic stroke with perfusion-imaging selection. $N$ Engl J Med 2015;372:1009-18 CrossRef Medline

23. Saver JL, Goyal M, Bonafe A, et al; SWIFT PRIME Investigators. Stent-retriever thrombectomy after intravenous t-PA vs. t-PA alone in stroke. $N$ Engl J Med 2015;372:2285-95 CrossRef Medline

24. Jovin TG, Chamorro A, Cobo E, et al; REVASCAT Trial Investigators. Thrombectomy within $\mathbf{8}$ hours after symptom onset in ischemic stroke. N Engl J Med 2015;372:2296-306 CrossRef Medline

25. Higashida RT, Furlan AJ, Roberts H, et al; Technology Assessment Committee of the American Society of Interventional and Therapeutic Neuroradiology; Technology Assessment Committee of the 
Society of Interventional Radiology. Trial design and reporting standards for intra-arterial cerebral thrombolysis for acute ischemic stroke. Stroke 2003;34:e109-37 CrossRef Medline

26. Bendszus M, Thomalla G, Knauth M, et al. Thrombectomy in patients ineligible for iv tPA (THRILL). Int J Stroke 2015;10:950-55 CrossRef Medline

27. Saver JL, Jahan R, Levy EI, et al; SWIFT Trialists. Solitaire flow res- toration device versus the Merci retriever in patients with acute ischaemic stroke (SWIFT): a randomised, parallel-group, non-inferiority trial. Lancet 2012;380:1241-49 CrossRef Medline

28. Nogueira RG, Lutsep HL, Gupta R, et al; TREVO 2 Trialists. Trevo versus Merci retrievers for thrombectomy revascularisation of large vessel occlusions in acute ischaemic stroke (TREVO 2): a randomised trial. Lancet 2012;380:1231-40 CrossRef Medline 